\title{
Review of Turning Points: Recent Trends in Adult Basic Literacy, Numeracy, and Language Education
}

Elisabeth Gee, Arizona State University

The impetus for this timely publication was several recent developments with potentially significant implications for the field of adult basic education (ABE), including new federal adult education authorization, the release of a new version of the GED test, and new content standards for ABE curricula. Turning Points is a volume in the long-standing series, New Directions for Adult and Continuing Education, and reflects the standard format for the series: a collection of short chapters, written in an accessible style, on a significant topic for adult and continuing educators. In this book, editor Alisa Belzer has recruited a group of contributors with an impressive range of experience in the field to address the

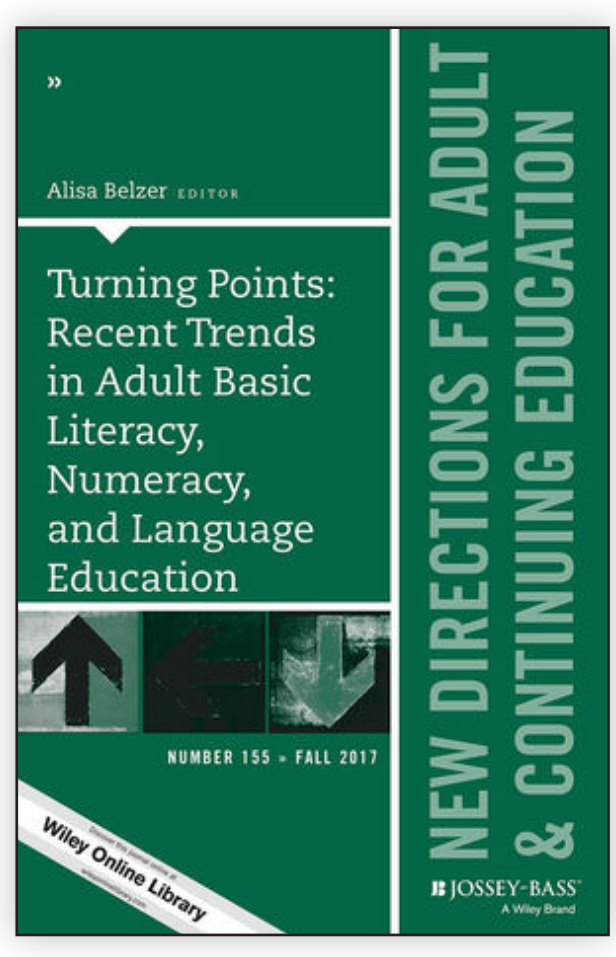
question of "where the field is in relation to where it has been and to where it might go" (p. 5), particularly in light of the new federal legislation, research findings, and changes in content standards and assessments.
In Chapter 1, Belzer sets the stage for this discussion with a clearly written and concise overview of federal policy initiatives that have shaped the provision of $\mathrm{ABE}$ over the last 25 years. As she points out, although the federal government provides less than half of the financial support for adult basic education, its policies play a significant role in shaping the field's priorities, programs, and practice. Belzer uses the metaphors of narrowing and focusing as a means of characterizing the potential consequences of policy initiatives. Focusing as applied to $\mathrm{ABE}$ implies a deepening understanding of and appreciation for the broad and complex nature of literacy practices in the context of learners' lives, with a corresponding emphasis on more differentiated, responsive, and informed educational strategies. In contrast, narrowing implies increasingly restrictive definitions of "what counts" in literacy education, often leading to one-dimensional 
conceptions of literacy, learners' lives, and appropriate instructional approaches. As Belzer discusses, in the 1990s, our understanding of adult literacy became more expansive, shifting from a view of literacy as a set of decontextualized skills to socially situated practices of meaning-making, and many literacy educators embraced a broader, social justice orientation to literacy education. At the same time, however, at the policy level, the trend clearly was towards a restrictive emphasis on linking adult basic education to employmentrelated skills and outcomes. This emphasis continues with the most recent Workforce Investment and Opportunity Act (WIOA), along with preparation for postsecondary education as a means of enhancing participants' employment opportunities.

The next several chapters address specific policies and initiatives in more depth. In Chapter 2, Eric Jacobson discusses the WIOA in greater detail, noting the increased emphasis on helping $\mathrm{ABE}$ students make transitions to further education or training, the integration of education and employment training, and serving the most vulnerable populations. Jacobson points out that holding ABE programs accountable for students' success in finding employment or higher wages does not account for wider economic trends that include the creation of more low-wage, low-skilled jobs. The broad conception of literacy that informs the OCED's Programme for the International Assessment of Adult Competencies (PIAAC), described by Sondra Stein in Chapter 3, offers a counterpoint to the WIOA's narrow emphasis on preparation for work. The PIAAC framework is based on a broad notion of competence in literacy, numeracy, and problem-solving in technologyrich environments. Stein illustrates in a concrete fashion how this framework can be used as a basis for designing instruction that helps learners develop skills through engagement with real-world tasks, texts, and contexts. In Chapter 4, Lennox McLendon offers a fascinating insider account of the decisions that led to the content and format of the latest version of the GED test, as well as the creation of additional credentialing options.

The remaining five chapters address broad topics such as the role of digital technologies in $\mathrm{ABE}$, educational services for adult immigrants, professional development for adult basic education practitioners, recent research findings, and gaps in the current knowledge base. Together, the chapters create a picture of a field that, on the one hand, has made progress in areas such as addressing digital literacies, creating more formal professional development opportunities, and developing a stronger research base. On the other hand, these accomplishments are fragmented; for example, professional development opportunities are unevenly distributed, and ABE still relies primarily on part-time teachers with few credentialing requirements. The tension between focusing versus narrowing in relation to the goals and priorities of adult basic education is evident throughout the chapters. For instance, in Chapter 5, David Rosen and Jenifer Vanek discuss how digital technologies have expanded our conceptions of literacies and texts, and they recruit the concept of "lifewide learning" to emphasize how new technologies have expanded our opportunities to learn across multiple life settings. These conceptions do not align easily with a narrow emphasis on passing standardized tests or obtaining entry-level jobs.

A strength of this volume is the overall quality of information, expertise of the authors, and clear writing style. While the book has nine chapters, it is less than 100 pages long, and written in a way that should be accessible to readers with varied degrees of familiarity with adult basic 
education practice or scholarship. The reader will encounter a number of acronyms for policies and programs, but these are explained in the text and are necessary given the topics. Newcomers to the field will find the book very helpful as a concise overview, while more experienced practitioners and researchers will find new information and perspectives. Unlike some edited volumes that lack coherence, Turning Points was obviously wellconceptualized, and the chapters fit together well.

The chapter authors attempt to provide a balanced view of recent policy trends and program initiatives, but a common theme is concern over the growing emphasis on linking $\mathrm{ABE}$ to employment and the pursuit of postsecondary education. Personally, I share this concern, but the current social and political climate does not bode well for any significant shift in federal policy directions in the near future. For most $\mathrm{ABE}$ practitioners, the question will be how to best support adult literacy learners within the constraints imposed by existing program and policy directives. The authors offer some broad suggestions, but this book is not intended to be a practical guide for $\mathrm{ABE}$ instruction or program development. It offers a broader perspective that can help practitioners put the challenges they face in a wider context, prompt further research, and hopefully stimulate continued attention to the role of the federal government in shaping policies and priorities in $\mathrm{ABE}$.

Belzer, A. (Ed.) (2017). Turning Points: Recent Trends in Adult Basic Literacy, Numeracy, and Language Education. New Directions for Adult \& Continuing Education (No. 155). San Francisco, CA: John Wiley \& Sons. 113 pages. \$29.00 Paperback; $\$ 23.99$ E-book. ISBN: 978-1-119-44378-0 